\title{
Client Retention Strategies and Customer Loyalty Development
}

\author{
Marya Mujayana ${ }^{1}$ \\ 1Program Studi S1 Ilmu Komunikasi STISIP Muhammadiyah Madiun
}

\begin{tabular}{ll}
\hline ARTICLE INFO & ABSTRACT \\
\cline { 2 - 3 } $\begin{array}{l}\text { Received June 2020 } \\
\text { Accepted June 2020 } \\
\text { Published July 2020 }\end{array}$ & $\begin{array}{l}\text { Since satisfied clients are the most significant resources of an } \\
\text { organization, organizations have been concentrating on creating } \\
\text { client maintenance and dedication programs. The key reason for } \\
\text { client maintenance endeavors is to guarantee keeping up } \\
\text { Keywords: Customer } \\
\begin{array}{l}\text { Retention, Customer Loyalty, } \\
\text { Marketing. }\end{array}\end{array}$ \\
$\begin{array}{l}\text { absociations with esteem including clients by diminishing their } \\
\text { endurance of the organization in exceptionally serious markets. } \\
\text { In this manner, this section begins with demonstrating the } \\
\text { noteworthiness of client maintenance promoting procedures for } \\
\text { the organization by uncovering the financial aspects of } \\
\text { maintenance advertising programs. Prerequisites for creating } \\
\text { powerful client maintenance systems are clarified. At last, in the } \\
\text { wake of talking about kinds of responsibility, this section finishes } \\
\text { by clarifying faithfulness projects and win-back systems. }\end{array}$ \\
\hline
\end{tabular}

\section{Introduction}

Relationship advertising turns into a basic key instrument for organizations in the present unique market in which client needs and inclinations are evolving quickly. These quick changes that happen in practically all business types, increment the significance of connections, and feature the need to go into systems of connections[1]. In this manner, organizations have been progressively concentrating on growing long haul gainful connections in business, inside and shopper markets so as to improve the worth that they convey to their clients.

Maintenance advertising techniques give numerous advantages to the organization in light of the fact that satisfied clients in-wrinkle their spending at an expanding rate, buy at a full edge as opposed to at markdown costs, and make working efficiencies[2]. In addition, getting new clients, for example, new record arrangement, credit searches, publicizing and limited time costs is expensive contrasted with hold ing a client[3]. The relationship startup costs that are caused when a client is obtained are very high and it might take quite a while to pick up benefit from the relationship to recoup those procurement costs. The record turns out to be increasingly productive and relationship upkeep expenses may in the long run decline as the connection between the organization and client extends over the time[4].

Moreover, clients who are happy with the organization are additionally ready to follow through on greater expenses since they get their feeling of significant worth from more than cost and in a set up relationship they are likewise liable to be less receptive to value bids offered by contenders [5]. Clients change from the organization for some 
reasons, for example, high, unjustifiable and tricky valuing, burden (e.g., sit tight for administration), center assistance disappointment (e.g., administration botches, charging mistake), administration experience disappointment (e.g., inconsiderate, unfeeling, lethargic staff practices), reaction to support disappointment (e.g., negative, no, hesitant), rivalry (e.g., accessibility of better other options), moral issues (e.g., dangerous, cheating) and automatic exchanging (moving). Client turning effects affects piece of the pie and gainfulness [6]. Overseeing client connections gives a wellspring of upper hand to the organizations. A connection transport creates between a client and association when there are advantages to the two players. Building a drawn out relationship is suitable just in conditions where both the client and the merchant are persuaded of the benefit of the relationship. Creating solid bonds with clients are ordinarily described as client maintenance programs.

\section{Research Methods}

Strategies for customer retention development: understanding client needs and inclinations, meeting and in any event, surpassing client desires, and conveying the high client esteem lead to consumer loyalty [7]. Clients, who are fulfilled, are bound to get satisfied and show conduct or potentially attitudinal dedication. Organizations that have a satisfied client base appreciate with high business execution, and accomplish increment in income development, portion of client, and client duty[8]. Fulfilled clients stay with working with the, and after some time clients' trust starts to develop. As clients' trust develops after some time, clients' dedication just as spending increments; since clients want to work with organizations with whom they have a demonstrated and acceptable connections. They would prefer not to face challenges. In addition, faithful clients are bound to make positive verbal exchange about the organization and attempt to urge different clients to work with the organization[3].

Rehash buys and new clients from referrals produce persistent income stream for the organization. Accordingly recognizing what drives client unwaveringness is significant for the organization's money related supportability. In the event that the organization needs clients who bring the organization more business and backer for the organization, the organization needs to show that it knows and cares its clients and prizes clients for their responsibility[7]. Administration quality, relationship quality, and by and large help fulfillment are among the elements that improve clients' goals to remain with a firm. An organization can keep up client maintenance and dedication through consumer loyalty, predominant assistance, faithfulness programs, abandonment investigation, grumbling taking care of, mass customization, client focusing on and database showcasing[4].

In the present showcasing condition, the manner in which organizations serve their clients is a significant wellspring of upper hand. Organizations use client support to grow long haul connections. Client care is significant in light of the fact that it very well may be utilized to separate a company's items, keep clients satisfied and thusly increment deals and benefits. Also, conveying unrivaled client care gives a chance to a firm to increase a reasonable bit of leeway in the commercial center. The quality and consistency of the administration are fundamentally critical for client maintenance[3]. 
An organization that needs to expand client maintenance must give better understanding and administration than its clients[1].

Unwavering quality, responsiveness, ability, get to, graciousness, correspondence, validity, security, understanding/knowing the client and physical assets are the determinants of administration quality[3]. Organization needs to convey solid client assistance and have the option to perform guaranteed administration reliably and constantly[5]. Being dependable, conceivable, and legit impacts the believability of the organization, and clients need to business with tenable organizations who can offer support liberated from hazard and uncertainty. Workers are required to have aptitudes and information to play out the administration too they ought to be able to pass on trust and certainty during the collaborations with customers.

\section{Result and Discussion}

The concept of customer commitment: customer commitment can be taken care of from two points of view: social and attitudinal devotion. Attitudinal satisfiedness incorporates disposition, for example, convictions, sentiments and buying goal. Though, conduct reliability reflects client buying conduct[7]. Conduct faithfulness is considered as the client's readiness to repurchase the item and to proceed with a relationship with the organization. Then again, attitudinal dependability communicates the degree of the client's mental connections and attitudinal support to the organization. Social dedication is the noticeable result of attitudinal reliability.

Client satisfiedness is a technique that makes common advantages for the organization just as clients. To accomplish client maintenance and dependability, organizations offer some incentive added advantages and prizes to their clients for their recurrent buys[5]. Then again, with satisfied clients, organizations can expand their benefit on the grounds that reliable clients are happy to purchase all the more oftentimes, buy strategically pitch and up-sell offers, prescribe items and administrations to other people, and go about as client referrers. Along these lines, the two players of the relationship profit by the advancement of long haul connections.

Organizations that need to advance longer-term client connections, keep up client maintenance, and diminish client surrender rates, should concentrate on understanding the drivers of client faithfulness and why clients remain. So that, organizations can create techniques that advance client maintenance. In endeavors to accomplish client unwaveringness, an organization should concentrate on building connections dependent on full of feeling parts of duty as opposed to calculative angles. As client maintenance methodology, full of feeling responsibility, which depends on fascination between accomplices, must be favored over calculative duty. Since calculative responsibility depends on steady weighing of the advantages of a relationship with an accomplice against the expenses of that relationship, relationship that depends exclusively on calculative duty in all likelihood not to keep going for quite a while.

Platform for customer loyaly: making customer loyalty is fundamental for the budgetary wellbeing of the organization. Long haul organization achievement relies upon the organization's capacity to develop from satisfiedness. In this manner, it is huge 
to guarantee and arrange the exercises that will encourage client maintenance and faithfulness. Dedication programs additionally encourage client maintenance. Devotion programs permit the organization to follow the purchasing conduct of the clients, create duty, and prize satisfied and continuous purchasers[3].

Organizations use reliability programs so as to energize continue buying and increment client maintenance[4]. Unwaveringness programs perform two critical jobs in CRM executions. To start with, they produce information that can be utilized to control client procurement, maintenance and improvement[5]. Also, dedication projects may fill in as a leave hindrance. Clients who have aggregated credits in a plan might be hesitant to leave the relationship. These projects as a rule take the state of participation and dedication card programs in which clients are compensated for their devotion. These prizes may extend from favored administrations to accepting focuses for cash spent, particular reason participation cards, rewards and limits.

Advantages and benefits help fulfill shoppers' requirements for status or comfort or sympathy, or every one of them simultaneously. Irregular thoughtful gestures delights clients. Incorporating advantages, benefits and arbitrary demonstrations of liberality to faithfulness programs require cautious intending to get ROI and these activities make clients satisfied, yet appreciative. For example, Interflora dispatches a web-based social networking effort in the UK so as to make lives of Twitter clients more joyful by sending them roses. Interflora tracks Twitter records to discover Twitter clients who should be brightened up. At that point the brand contacts with them so as to send them roses as an amazement. This arbitrary thoughtful gesture delights clients, begins discussion about the brand and can be appealing to pull in first time clients.

Brief strategy to win competition: client review the board is tied in with winning back the clients who have either decreased their degree of business exchanges with the organization or have halted exchange by any stretch of the imagination. It plans to revamp associations with the clients who have surrendered the organization. Recover the executives' focuses on previous clients who have involvement in the organization. In customary selecting, division is exclusively founded on the outside information and correspondence is coordinated for the most part one route toward the possibility. With recover the executives promoting can depend on restrictive database for division and correspondence all the more regularly started by the lapsed clients. Measuring the estimation of client is basic in recapture the board. Without knowing the estimation of clients it is hard to tell how much the organization ought to spend so as to reacquire the client. Customization, separation and wow systems are among the recapture methodologies for lost clients.

\section{Conclusion}

Loyal customers give a strong base of income stream for the organization just as they may speak to development potential; since they purchase more items and administrations from the organization after some time. Company must focus on high fulfillment; since high fulfillment makes a passionate bond with the firm and thus, this will prompt client maintenance. Giving unrivaled worth, which will enchant clients, is 
the most dependable approach to guarantee manageable consumer loyalty and client reliability.

Loyal customers represent a significant measure of organization benefits; subsequently, an organization ought not chance to lose a client by overlooking their grumblings. Organizations can keep up client maintenance and satisfiedness when they pick their objective markets cautiously; on the grounds that an organization can't fulfill everybody in the market. Along these lines, organizations need to discover and keep the correct clients who are gainful for the organization to serve.

Loyalty can both upgrade and dissolve connection between the organization and its clients. Emotional responsibility endeavors upgrade the connection between the organization and clients. In this manner, organizations require to target making emotional responsibility; on the grounds that full of feeling duty bolsters the improvement of manageable and long haul re-Loyalty programs are used so as to keep up client maintenance and empower continue buying. Satisfiedness programs perform two critical jobs in CRM executions connections, diminishes exchanging aims and expands the support goals of clients. Client who need to pick up remunerations keep on working with the organization.

\section{References}

[1] A. Thyro and W. E. Kilbourne, "Self-enhancement and individual competitiveness as mediators in the materialism / consumer satisfaction relationship," vol. 92, no. July, pp. 189-196, 2018, doi: 10.1016/j.jbusres.2018.07.023.

[2] E. S. Singer, R. E. Merritt, D. M. D. Souza, and D. Susan, "Patient Satisfaction after Lung Cancer Surgery: Do Clinical Outcomes affect HCAHPS Scores?," Ann. Thorac. Surg., 2019, doi: 10.1016/j.athoracsur.2019.06.080.

[3] K. Joo and S. Managi, "Liberalization of a retail electricity market: Consumer satisfaction and household switching behavior in Japan 2 , " Energy Policy, vol. 110, no. July, pp. 675-685, 2017, doi: 10.1016/j.enpol.2017.07.048.

[4] T. M. Nisar and G. Prabhakar, "What Factors Determine e-Satisfaction and Consumer Spending in e-Commerce Retailing?," J. Retail. Consum. Serv., vol. 39, no. July, pp. 135-144, 2017, doi: 10.1016/j.jretconser.2017.07.010.

[5] A. Meesala and J. Paul, "Service Quality, Consumer Satisfaction and Loyalty in Hospitals: Thinking for the Future," J. Retail. Consum. Serv., no. October 2015, pp. 1-9, 2016, doi: 10.1016/j.jretconser.2016.10.011.

[6] M. Kim, D. Van Hout, and H. Lee, "Degree of satisfaction-di ff erence ( DOSD ) method for measuring consumer acceptance : Comparative and absolute measures of satisfaction based on signal detection theory," Food Qual. Prefer., vol. 68, no. November 2017, pp. 167-172, 2018, doi: 10.1016/j.foodqual.2018.03.003.

[7] H. Khosroshahi, M. Rasti-barzoki, and S. R. Hejazi, A game theoretic approach for pricing decisions considering CSR and a new consumer satisfaction index using transparency-dependent demand in sustainable supply chains. Elsevier B.V., 2018.

[8] F. R. Harker, D. Hunter, A. White, K. Richards, M. Hall, and C. Fullerton, "Postharvest Biology and Technology Measuring changes in consumer satisfaction associated with kiwifruit ripening: A new approach to understand human- 
product interactions with fruit," Postharvest Biol. Technol., vol. 153, no. October 2018, pp. 118-124, 2019, doi: 10.1016/j.postharvbio.2019.03.010. 